\title{
Learning A La Carte: A Theory-Based Tool For Maximizing Student Engagement
}

\author{
Jeremy Sibold, Ed.D., ATC, University of Vermont, USA
}

\begin{abstract}
It is well-established that motivation is a critical component of one's best performance of a task. A primary model in the field of motivation is the self-determination theory (SDT). The three pillars of SDT include competency, autonomy, and relatedness; when supported these have been shown to improve the quality, consistency, and persistence of one's effort at a task. It is the purpose of this article to examine relevant SDT research, and utilize relatable trans-disciplinary findings in support of the discussion of a novel course development technique that maximizes student engagement in the higher education environment - the assessment menu.
\end{abstract}

Keywords: Assessment; Grading; Syllabus; Engagement; Motivation to Learn

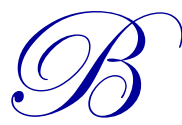

eing motivated may be simply defined as being moved to complete a task (Ryan \& Deci, 2000a), and includes both the intensity and direction of one's effort (Weinberg \& Gould, 2014). Intensity refers to the effort a person puts into a task, whereas direction relates to in which tasks a person chooses to engage (Weinberg \& Gould, 2014). A leading model of human motivation is the self-determination theory (SDT), which examines social and environmental factors that affect and subsequently lead to optimal and sustained human motivation (Ryan \& Deci, 2000b). Indeed, it has been applied to myriad contexts including health behavior, work, sport, and education. It is the purpose of this article to examine relevant SDT research and utilize relatable findings to support the discussion of a novel course development technique that maximizes student engagement in the higher education environment.

\section{Self-Determination Theory}

SDT has identified three primary factors that have been shown to enhance motivation: competence, autonomy, and relatedness (Ryan \& Deci, 2000b). Practically speaking, SDT suggests that humans are more likely to engage in behavioral contexts wherein they feel capable of performing given tasks in which they are interested, and where they have a choice or control over primary aspects of the task environment, as opposed to situations with the opposite profile. It is well established that behavioral settings that support these three constructs result in enhanced motivation among participants, a fact not to be ignored by any leader who wishes to motivate participants to engage and perform their best (Ryan \& Deci, 2000b).

Within the construct of motivation, it is important to consider the source of motivation; that is, whether one is motivated by external or internal factors. Extrinsic motivation can be defined as being motivated to achieve a specific outcome, reward, or standard; whereas intrinsic motivation refers to being motivated to perform a behavior because it is personally rewarding, interesting, and satisfying (Ryan \& Deci, 2000a). For example, one student may work quite hard on a project because a passing grade depends on it (extrinsic), versus a classmate who may work just as hard (or harder) because interested in the topic area as it relates to background and future career goals (intrinsic). In reality, human motivation does not exist in this dichotomy of purely extrinsic versus purely intrinsic, but along a continuum of motivation that drives behavior (Ryan \& Deci, 2000b).

With regard to competency and autonomy, the research has shown that while extrinsic factors can be motivating acutely, intrinsically motivated behavior, in which participants feel a sense of control and competence, results in superior learning outcomes (Ryan \& Deci, 2000a). For example, it has been shown that autonomous motivation where participants have volitional choice and thus, control, is positively related to overall academic performance (Kusurkar, Croiset, \& Ten Cate, 2011; Vansteenkiste, Lens, \& Deci, 2006). The opposite is true in controlling 
environments, which have been associated with diminished learning and lower overall academic achievement (Grolnick \& Ryan, 1987). In other words, giving students a sense of control over their learning, while providing feedback and coaching that cultivates feelings of content mastery and competence in the topic area, should lead to increased intrinsic motivation and engagement with course material.

With regard to the relatedness component of SDT, academic environments in which students feel connected to the information or learning task, and/or where the relevance of the material is clear to the student, should enhance student motivation and engagement. Indeed, it has been shown that by clearly defining the personal relevance of the material, thus underscoring the importance of the content for students, instructors may enhance student motivation and engagement where it may otherwise be lacking (Assor, Kaplan, \& Roth, 2002; Deci, Eghrari, Patrick, \& Leone, 1994). In a series of empirically-based tips for enhancing intrinsic motivation in students, Kusurkar, Croiset, and Ten Cate (2011) highlighted the importance of providing individualized and optimized learning challenges to students, while bridging the gap between course content and practical relevance of the material with real-world examples. In addition, they recommend giving students choice over learning methods and modalities where appropriate such that "Being involved in some of the planning helps the students feel closely related to the course and enhances their intrinsic motivation to do the things required. .." (p. 981). By highlighting relevance and relatedness, and by offering students a choice of learning or assessment methods, instructors may tap into the innate psychological needs of competence, autonomy, and relatedness; and in doing so may enhance student engagement and overall motivation for learning. One tool designed with these outcomes in mind is the assessment menu.

\section{Assessment Menu Background}

By giving learners control with regard to how they may achieve a prescribed objective, faculty can empower and motivate students to engage with course content in a way that is tailored to their own learning style, free of the restrictions of a traditional uniform method of assessment that may not be congruent with all individual learning styles, backgrounds, or capabilities. This a la carte system can also serve to decrease assessment workload in the increasingly large and inter-professional classroom environment.

Empirical evidence from my own research and training in the rehabilitation and exercise science arena has shown, for example, that choice of exercise modality and/or exercise intensity leads to improved adherence to, and psychological impact of, exercise participation (Ekkekakis, Hall, \& Petruzzello, 2004; Parfitt, Rose, \& Burgess, 2006; Parfitt, Rose, \& Markland, 2000; Williams, 2008). These data have interesting intersections with the broader context of human decision making and behavior, including in the classroom environment. In particular, it seems that, to use the exercise example, despite having to complete a challenging exercise bout (which for many exercisers can serve as a barrier to exercise adoption or participation), when given control over their preferred mode and intensity of exercise, the psychological benefits of the exercise bout are significantly greater than groups for whom exercise is prescribed. Consequently, it is conceivable that exercisers given control over exercise mode and intensity may be more likely to adopt and adhere to sustained exercise behavior than those for whom it was controlled and prescribed, due to being more intrinsically motivated to do so.

Having taught in higher education over the last two decades, it has become increasingly clear that students will display similar results to these seemingly disparate clinical exercise data. I have observed that when forced to complete a prescribed assignment that is perceived as challenging, threatening, novel, and so on, both the quality of the work and subsequently the overall quality of the student experience is negatively affected for some. In some cases, I have seen it lead to the avoidance of subsequent class engagement and, ultimately, failure. However, when given an equally challenging, yet diverse menu of relevant and practical options as to how they can show their knowledge in the very same content area, students perceive the experience as less threatening and more interesting, and ultimately engage to produce higher quality work. While anecdotal, I believe that this is a product of the environment where students are allowed an appropriate level of control and autonomy as to how and when they would show their developing acumen in the content area in a self-selected format more congruent with individual differences in competence and confidence. In the end, it is my opinion that by giving students a flexible menu of potential assessment tasks, faculty can directly speak to the innate needs of competence, autonomy, and relatedness as identified in the SDT model (Ryan \& Deci, 2000b), and in doing so enhance student engagement and sustained intrinsic motivation by recognizing students as primary stakeholders in the educational arena. 
A parallel benefit that I have found has also been that with good planning, this a la carte system can reduce variability in faculty workload across a semester while at the same time making students feel more individual-level attention and feedback, particularly in the large classroom environment. By simply varying the dates in which different assessment choices are due while capping the number of accepted responses to each assignment, the instructor can take advantage of controlling the inevitable volume of grading even while simultaneously handing control to students for individual assessment choices. In doing so, instructors can enjoy fewer grading tasks at any given due date, thus allowing richer and more individualized feedback to students, which has also been linked to intrinsic motivation for learning (Kusurkar et al., 2011).

\section{Assessment Menu Development}

Obviously, information on how students are to be assessed in any given course is a critical component of the course syllabus. It is common for a syllabus to be presented to a class on day one, to set the tone for the course, presenting course expectations, schedules, and learning objectives. However, in many instances this occurs in a unidirectional fashion, that is where the structure and methods of a course have been designed from the instructor perspective alone, with little to no input from the student cohort (Blinne, 2013). However, students who read a well-developed syllabus with clear objectives and requirements are likely to believe that the course has been designed to support them in reaching their academic goals (Slattery \& Carlson, 2005).

It is my contention that in addition to evidence-based recommendations for syllabus development (Blinne, 2013; Canada, 2013; Parkes \& Harris, 2002; Saville, Zinn, Brown, \& Marchuk, 2010; Slattery \& Carlson, 2005), faculty should, whenever possible, consider the inclusion of an assessment menu where students may choose how and when they are assessed on content knowledge and specific learning objectives. This simple addition to the standard course syllabus may enhance student engagement and motivation for learning by directly addressing the fundamental components of SDT.

The development of the assessment menu is not difficult. In essence, one may consider this tool similar to any other menu. Do you want an entrée and two sides? Or an appetizer, entrée, and dessert? All have different prices and caloric impact, yet the variety of the menu itself allows consumers to pick what is best for them with regard to preference, tolerance, and health goals. With regard to the academic assessment menu, I would offer the following two disparate examples for consideration - an assessment menu from syllabus A, the "typical" syllabus (see Figure 1), and syllabus B, the a la carte approach (see Figure 2).

Figure 1. Syllabus A: The Traditional Course

\begin{tabular}{|c|c|c|}
\hline Learning Assessment & Due Date & Points Available \\
\hline Multiple choice quizzes & Weeks $2,4,6,8,10$ & 20 pts per quiz \\
\hline Mid-term exam & October $15^{\text {th }}$ & $50 \mathrm{pts}$ \\
\hline $\begin{array}{l}\text { Research paper, APA style, } 10-15 \text { pages. } \\
\text { Topic: To be assigned in class during week } 3\end{array}$ & October $31^{\text {st }}$ & $50 \mathrm{pts}$ \\
\hline Final Exam & December $5^{\text {th }}$ & $100 \mathrm{pts}$ \\
\hline
\end{tabular}

In syllabus A, there exists a very typical set of assessment milestones, each with a prescribed due date, point value, and in some cases, topic area. In this example, the instructor has ultimate control over how and when learning is evaluated. However, one may argue that in presenting these assessment opportunities, the instructor is threatening the evidence based needs of autonomy, competence, and relatedness of the student cohort. For example, for students who are not strong writers, why force them to write or restrict them to one written medium to earn the grade? It is plausible that, when faced with this challenge, a student may lose the impact of the learning the paper was designed to facilitate due to the angst and challenge of the writing process itself. A second example is a learner who may not consistently score well on multiple choice or other rote type examinations, yet can express content knowledge in the written word in a rich and applied fashion. If corralled into a testing format that is not congruent with their personal strength and/or confidence, it may result in a situation where the test is not a valid indicator of the students' competency in a content area. In addition, students who approach the challenge with trepidation may only reinforce their diminished self-efficacy with a low score. In any case, it seems that by restricting an entire class to a 
proscribed set of assessments may in fact marginalize even strong students and driven learners by evaluating them in a way that is incongruent with individual styles of learning and expression.

Figure 2. Syllabus B- The Assessment Menu

\begin{tabular}{|c|c|c|c|}
\hline Learning Assessment & Due Date & Points Available & Comments \\
\hline Multiple choice quizzes & $\begin{array}{c}\text { Weeks } \\
2,4,6,8,10\end{array}$ & $\begin{array}{l}20 \text { pts per quiz } \\
(100 \text { pts total }) \\
\text { *If you choose this option, } \\
\text { you must complete all } 5 \\
\text { quizzes for the course. }\end{array}$ & $\begin{array}{l}\text { *Maximum } 25 \text { students in } \\
\text { this option. } \\
\text { Sign up posted on course } \\
\text { website, first come, first } \\
\text { serve. }\end{array}$ \\
\hline Mid-term exam & October $15^{\text {th }}$ & 50 pts & Required \\
\hline $\begin{array}{l}\text { Research paper } \\
\text { APA style, } 10-15 \text { pages. }\end{array}$ & $\begin{array}{l}\text { Topic 1: Oct } 1^{\text {st }} \\
\text { Topic 2: Oct } 10^{\text {th }} \\
\text { Topic 3: Oct } 20^{\text {th }} \\
\text { Topic 4: Oct } 30^{\text {th }} \\
\text { Topic 5: Nov 10th }\end{array}$ & $\begin{array}{l}50 \text { pts } \\
\text { *Maximum } 2 \text { papers per } \\
\text { student. Topics and rubric } \\
\text { TBA in class. }\end{array}$ & $\begin{array}{l}\text { *Only } 10 \text { papers accepted } \\
\text { for each topic. } \\
\text { Sign up posted on course } \\
\text { website, first come, first } \\
\text { serve. }\end{array}$ \\
\hline $\begin{array}{l}\text { Research based debate } \\
\text { Topic area: Debate group may choose } \\
\text { course specific debate, with instructor } \\
\text { approval/guidance. }\end{array}$ & Nov $15^{\text {th }}$ & $\begin{array}{l}50 \text { pts } \\
\text { Requirements and rubric } \\
\text { TBA in class. }\end{array}$ & $\begin{array}{l}* \text { Only } 10 \text { slots available }(2 \\
\text { teams of } 5) \text {. } \\
\text { Sign up posted on course } \\
\text { website, first come, first } \\
\text { serve. }\end{array}$ \\
\hline $\begin{array}{l}\text { Web site design project: } \\
\text { Students will develop a website on a } \\
\text { content area designed to educate the lay } \\
\text { public (you must pick a target } \\
\text { population) where you deliver education } \\
\text { in a content area related to the class in a } \\
\text { way that is engaging, meaningful, and } \\
\text { empirically sound, but communicated in } \\
\text { a way that it appropriate for the target } \\
\text { population. }\end{array}$ & Nov $5^{\text {th }}$ & $\begin{array}{l}50 \text { pts } \\
\text { Requirements and rubric } \\
\text { TBA in class. }\end{array}$ & $\begin{array}{l}\text { *Only } 10 \text { groups of } 1-4 \\
\text { students are allowed for } \\
\text { this project. } \\
\text { Sign up posted on course } \\
\text { website, first come, first } \\
\text { serve. }\end{array}$ \\
\hline $\begin{array}{l}\text { Oral presentation: } \\
\text { Students will plan and deliver a } 20 \mathrm{~min} \\
\text { presentation to the class during the final } \\
\text { week of classes, on a topic area from the } \\
\text { course. }\end{array}$ & $\begin{array}{l}\text { TBA Last week of } \\
\text { class. }\end{array}$ & $\begin{array}{l}50 \text { pts } \\
\text { Requirements and rubric } \\
\text { TBA in class. }\end{array}$ & $\begin{array}{l}\text { * Only } 5 \text { speakers accepted. } \\
\text { Sign up posted on course } \\
\text { website, first come, first } \\
\text { serve. }\end{array}$ \\
\hline Final Exam & December $5^{\text {th }}$ & 100 pts & Required \\
\hline
\end{tabular}

In contrast, syllabus B will allow several advantages to the class as well as the instructor. By offering a menu of assessment options, the instructor allows students to approach evaluation challenges that are aligned with their individual strengths (i.e., competency). Also, by allowing this level of autonomy, the instructor can maximize student engagement while at the same time clearly communicating that the responsibility for intellectual growth rests squarely on the students' shoulders, as opposed to risking the chance that the student cohort become passive learners due to perceived lack of control, absorbing (or not) delivered information from the instructor and compartmentalizing it in a way that is aimed solely at scoring well on an exam versus considering the content broadly and in a way that is related to career interests and goals.

As a third possible advantage, consider the increasingly common large class format in higher education. A primary component necessary to maximize student engagement and motivation is that of timely and thorough instructor feedback (Kusurkar et al., 2011). If faced with 50, 75, or even 100 research papers to read on one topic area, an instructor is very limited in the depth and quantity of feedback provided to each student. But with simple controls in place in an a la carte menu, the instructor can delimit assessment options to, for example, 10 per due date. In this 
example, instead of facing the monumental task of providing in depth feedback on hundreds or thousands of pages of material on one due date, the instructor can balance the workload in order to be in control of how many assignments need grading at any given time. The result is an instructor who similarly feels control and autonomy over the critically important process of providing feedback to students. Imagine the difference in the class experience for students and instructors alike where there is a system in place that allows all stakeholders to have control and autonomy in the course progression.

Clearly there are limitations to this a la carte system and it may not be applicable to all courses. For example, in no way does this suggest that we as learning guides allow students to only choose the easiest formats. In fact, with simple rules regarding how many (minimum and maximum) of any one kind of assessment can be chosen from any given category, the instructor can diversify assessments to ascertain a much richer and more individualized picture of each student's strengths and learning needs. For example, in syllabus B, it does not allow a student to take only the mini-quizzes and skip more challenging writing, exams, or complex projects. It simply allows them to balance learning assessments against their personal strengths.

In addition, this system is not advocating that we allow students to choose not to write as a learning tool. For example, an instructor would likely not want a student only completing multiple choice exams in an upper-level class that engages with current research literature, but would want the students to be able to collate the empirical evidence that exists and then be able to synthesize a position in a particular topic area and communicate it in the written word. To do this, they must write. However, to restrict students to one topic area, or one format (as seen in syllabus A), the instructor may unknowingly miss an opportunity to uncover and cultivate a student's gift of producing research-based content aimed at the general public (i.e., mass media), as opposed to reinforcing students' belief that they are not strong scientific writers by restricting them to a specific format. In allowing students to choose a format for their writing (syllabus B), the instructor can address not only competency, but also allow students to interact autonomously with the same research literature as others in the class, but in a way that is related to their possible career path - a freelance health writer, for example. In doing so, it is my belief that students will be more likely to approach the assignment with high motivation and self-efficacy, as they are interacting with course content in a way that is relevant to them as individuals. Add to that the aforementioned advantage of rolling due dates that allow more thorough feedback in a more timely manner, and the simple assessment menu has supported a positive learning environment for both teacher and student.

Again, it is important to note that the suggested tool is one that is based on theoretical as well as anecdotal data; it has not been rigorously evaluated with regard to its influence on motivation or academic outcomes in a student cohort. Moving forward, research is necessary to examine the impact of assessment menu based curricula on student outcomes in randomized control studies. A simple study design where baseline motivational and content knowledge evaluations are compared to post-course scores in the same domains, with group-wise comparisons made for traditional and a la carte cohorts, may be an important next step in the validation of the assessment menu as a stand-alone curricular model.

\section{CONCLUSIONS}

The purpose of this article is to present a theoretically-supported tool that enhances student engagement and motivation. Specifically, the use of the assessment menu in course design supports the well-documented need for autonomy, competence, and relatedness as cornerstones of intrinsic motivation to complete a task as suggested by the self-determination theory (Ryan \& Deci, 2000b). This tool is not presented as the panacea for all courses, nor is it without limitations as discussed. However, by suggesting this a la carte system of learning assessment in which students are given a voice and choice as to how they demonstrate their learning in a course, it is my hope to facilitate a broader conversation regarding the assessment of learning based on individual levels of competence and confidence. The assessment menu concept is one possible idea that can simultaneously speak to student motivation and engagement, as well as potentially allowing instructors the opportunity to connect with students individually based on their respective learning styles while at the same time balancing workload across the academic calendar. 


\section{AUTHOR BIOGRAPHIES}

Dr. Sibold has worked higher education since 1999, and has taught in both liberal arts and large, research I institutions. He is currently serving as an Associate Professor and Department Chair in the College of Nursing and Health Sciences at the University of Vermont. He has received teaching excellence awards at two separate institutions, and has also served, or is serving in leadership roles in and around curricular development and collegewide assessment in a variety of settings. E-mail: jeremy.sibold@med.uvm.edu

\section{REFERENCES}

Assor, A., Kaplan, H., \& Roth, G. (2002). Choice is good, but relevance is excellent: Autonomy-enhancing and suppressing teacher behaviours predicting students' engagement in schoolwork. British Journal of Educational Psychology, 72(2), 261-278.

Blinne, K. C. (2013). Start with the syllabus: HELPing learners learn through class content collaboration. College Teaching, 61(2), 41-43. doi: 10.1080/87567555.2012.708679

Canada, M. (2013). The syllabus: A place to engage students' egos. New Directions for Teaching \& Learning, 135, 37-42. doi: $10.1002 / \mathrm{t} 1.20062$

Deci, E. L., Eghrari, H., Patrick, B. C., \& Leone, D. R. (1994). Facilitating internalization: The self-determination theory perspective. Journal of Personality, 62(1), 119-142.

Ekkekakis, P., Hall, E. E., \& Petruzzello, S. J. (2004). Practical markers of the transition from aerobic to anaerobic metabolism during exercise: Rationale and a case for affect-based exercise prescription. Preventive Medicine, 38(2), 149-159.

Grolnick, W. S., \& Ryan, R. M. (1987). Autonomy in children's learning: An experimental and individual difference investigation. Journal of Personality and Social Psychology, 52(5), 890-898. doi: 10.1037/0022-3514.52.5.890

Kusurkar, R. A., Croiset, G., \& Ten Cate, T. J. (2011). Twelve tips to stimulate intrinsic motivation in students through autonomy-supportive classroom teaching derived from self-determination theory. Medical Teacher, 33(12), 978-982. doi: 10.3109/0142159X.2011.599896

Parfitt, G., Rose, E. A., \& Burgess, W. M. (2006). The psychological and physiological responses of sedentary individuals to prescribed and preferred intensity exercise. British Journal of Health Psychology, 11(Pt 1), 39-53. doi: 10.1348/135910705x43606

Parfitt, G., Rose, E. A., \& Markland, D. (2000). The effect of prescribed and preferred intensity exercise on psychological affect and the influence of baseline measures of affect. Journal of Health Psychology, 5(2), 231-240. doi: $10.1177 / 135910530000500213$

Parkes, J., \& Harris, M. B. (2002). The purposes of a syllabus. College Teaching, 50(2), 1.

Ryan, R. M., \& Deci, E. L. (2000a). Intrinsic and extrinsic motivations: Classic definitions and new directions. Contemporary Educational Psychology, 25(1), 54-67. doi: 10.1006/ceps.1999.1020

Ryan, R. M., \& Deci, E. L. (2000b). Self-determination theory and the facilitation of intrinsic motivation, social development, and well-being. The American Psychologist, 55(1), 68-78.

Saville, B. K., Zinn, T. E., Brown, A. R., \& Marchuk, K. A. (2010). Syllabus detail and students' perceptions of teacher effectiveness. Teaching of Psychology, 37(3), 186-189. doi: 10.1080/00986283.2010.488523

Slattery, J. M., \& Carlson, J. F. (2005). Preparing an effective syllabus. College Teaching, 53(4), 159-164.

Vansteenkiste, M., Lens, W., \& Deci, E. L. (2006). Intrinsic versus extrinsic goal cntents in self-determination theory: Another look at the quality of academic motivation. Educational Psychologist, 41(1), 19-31. doi: 10.1207/s15326985ep4101_4

Weinberg, R. S., \& Gould, D. (2014). Foundations of sport and exercise psychology (6 ${ }^{\text {th }}$ ed.). City, ST: Human Kinetics, Champaign, IL

Williams, D. M. (2008). Exercise, Affect, and Adherence: An Integrated Model and a Case for Self-Paced Exercise. Journal of Sport \& Exercise Psychology, 30(5), 471-496. 